\title{
Infection and interferon production in systemic juvenile chronic arthritis: a prospective study
}

\author{
A. DE VERE-TYNDALL, TERESA BACON, RUTH PARRY, * \\ D. A. J. TYRRELL, ${ }^{*}$ A. M. DENMAN, AND BARBARA M. ANSELL \\ From the Divisions of Rheumatology and ${ }^{*}$ Communicable Diseases, Northwick Park Hospital and Clinical \\ Research Centre, Watford Road, Harrow, Middlesex
}

SUMmaRY Twenty-four episodes of disease exacerbation in 19 children suffering from systemic juvenile chronic arthritis were studied. Sixteen of these were preceded by an infection $\left(\chi^{2}=20 \cdot 14\right.$, $\mathrm{p}<0.001)$, mostly of the upper respiratory tract. In the 10 cases seen during an infection causative agents were identified in 5 (herpes simplex, rhinovirus, and on 3 occasions streptococcus). The total number of infections was not increased when compared with infection rates predicted by several reported studies.

In the absence of clinical infection, specific antibody titres to a panel of microbial antigens were similar to those of a control group but with a trend toward higher titres in patients with hypergammaglobulinaemia. Interferon (IFN) responses were not defective, though sequential in-vitro IFN production from peripheral blood mononuclear cells (PBM) fluctuated considerably in the same patients, occasionally being absent with no obvious clinical correlate. IFN- $\alpha$ was induced by stimulation with Newcastle disease virus (NDV), and the mean responses of the patients were significantly greater than those of controls. IFN- $\gamma$ production on phytohaemagglutinin (PHA) stimulation was similar in patients and control groups. IFN was not detected in any of the sera from patients or controls.

Historically, episodes of infection frequently appear to precede exacerbations of disease activity in systemic juvenile chronic arthritis (JCA). The exact relationship is difficult to establish, as the disease itself has many clinical features of an acute infection and may be associated with increased levels of nonspecific antibody. ${ }^{2}$ Moreover, some viral illnesses associated with arthritis such as rubella infection may persist for months or years and mimic $\mathrm{JCA}^{3-5}$

This prospective study was designed to investigate the relationship between viral, bacterial, and mycoplasma infections and disease activity in established cases of systemic JCA.

\section{Patients and methods}

Patients. Nineteen children ( 13 boys and 6 girls) were studied for 1 to 15 months (mean 6.6 months). All patients had systemic JCA as defined by EULAR

Accepted for publication 10 February 1983.

Correspundence to Dr Barbara M. Ansell, Division of Rheumatology, Clinical Research Centre, Watford Road, Harrow, Middlesex HA1 3 UJ. criteria $^{6}$ and were aged between 1 and 15 years (mean $9 \cdot 2$ years). There were 16 established cases (disease duration 1 to 10 years, mean 5 years) and 3 newly diagnosed (duration 6-12 weeks, mean 8.6 weeks). On entry to the study each patient was seen monthly and where possible during any episode of infection or disease exacerbation. If neither of these occurred after 6 months, then study visits were suspended until such time as either ensued. For each patient a daily diary of 18 simple symptoms or events relating to disease activity and infections was recorded by the parents, as well as a monthly family infection record. These were retrospectively analysed at each visit by the same physician (A.T.), who also performed a clinical assessment consisting of the parents' impression of disease activity, measurement of temperature, active joint count, and examination of ears, nose, throat, lymph nodes, liver, spleen, respiratory system, and heart. On each occasion specimens were collected for full blood count, erythrocyte sedimentation rate, C-reactive protein, serum immunoglobulins $\operatorname{IgG}, \operatorname{IgA}$, and $\operatorname{Ig} M$, and antibody titres to a panel of microbial antigens consisting of adenovirus, measles, respiratory syncytial 
virus, influenza virus $\mathrm{A}$ and $\mathrm{B}$, rubella virus, $\mathrm{Myco-}$ plasma pneumoniae, and antistreptolysin 0 . Throat swabs were cultured for viruses, bacteria, and $M$. pneumoniae and nasal aspirates and swabs for viruses and bacteria. When available, urine and stool specimens were similarly cultured. Whenever a virus was isolated, sequential neutralising antibody titres were performed on stored sera. Interferon (IFN) was measured in all serum specimens and in-vitro IFN- $\alpha$ and IFN- $\gamma$ production assessed from peripheral blood mononuclear cell (PBM) stimulation. Nine patients were taking glucocorticosteroids (maximum dose $10 \mathrm{mg}$ alternating with $2 \mathrm{mg}$ daily), and 8 were established on long-acting antirheumatic agents.

Control subjects. Twenty-four children (15 boys and 9 girls) aged between 5 and 16 years (mean $11 \cdot 5$ ) presenting to the clinic with noninflammatory disease (retropatellar pain, hypermobility syndrome, or psychogenic limb pains) required a full blood count as part of their routine assessment, and $8 \mathrm{ml}$ of blood was obtained for the blood studies as performed on the patients. All had a normal ESR and C-reactive protein, and no further investigations were performed. None had had a clinical infection in the month prior to venesection, nor was there any suggestion that their symptoms could be related to infection. Microbiological cultures were not performed on the control group.

Definitions. Systemic exacerbation: typical evening fevers and increased joint activity for greater than 3 days; may also be accompanied by typical rash, lymphadenopathy, or hepatosplenomegaly.

Exacerbation in joint activity only: objective increase in active joint count or more than 3 days of increased symptoms (doubled early morning stiffness or slowness and definite loss of function).

Common cold: symptoms present for more than 24 hours and objective rhinorrhoea; greater than 'aborted minimal cold' by Salisbury Common Cold Unit criteria. ${ }^{7}$

Sore throat: duration longer than 24 hours with difficulty in swallowing or objective signs.

Virology. At each visit nose and throat swabs were collected and when present nasal secretions were aspirated by a neonatal mucus trap. Specimens were collected into viral transport medium on melting ice and inoculated into $\mathrm{HeLa}, \mathrm{MRC} 5$, and secondary baboon kidney cell cultures within 3 hours of collection. Stool specimens, when obtained, were stored at $-70^{\circ} \mathrm{C}$ prior to inoculation into tissue culture and examination by electron microscopy. ${ }^{8}$ All respiratory specimens which were negative on testing in the above mentioned cell cultures were retested in secondary rhesus kidney cells.

Whenever a virus was isolated it was used to determine neutralising antibody titres in the sera col- lected from that patient on the same day as the isolation and at least one other collected up to 3 months later. $^{910}$

The nasal swabs and aspirates were examined for the presence of coronavirus antigens by means of an enzyme-linked immunoabsorbent assay (ELISA). Paired sera were tested by ELISA for antibody against a representative strain of each of the 2 subtypes of human coronavirus, 229E and HCV Paris. ${ }^{11}$

Bacteriology. Nose and throat swabs were cultured routinely on each occasion with specimens either collected into transport medium or plated out directly on to blood and chocolate agar plates by the bedside.

Mycoplasma pneumoniae. Throat swabs were collected into specialised $M$. pneumoniae transport medium and delivered to the laboratory within 3 hours.

Antibody titres. Complement fixing antibody titres (CFT) against adenovirus, measles virus, respiratory syncytial virus (RSV), influenza $A$ and $B$ virus, and $M$. pneumoniae were measured in each sample. Rubella virus antibodies were measured by radial immune haemolysis and antistreptolysin 0 titres (ASOT) by haemagglutination inhibition. When streptococcal infection was suspected, antihyaluronidase and anti-DNAase $B$ titres were also measured.

Serum immunoglobulins $G$, A, and $M$ were assayed by laser nephelometry and C-reactive protein by radial immunoprecipitation.

Interferon. Peripheral blood mononuclear cells (PBM) were separated from $4 \mathrm{ml}$ of heparinised blood on a Ficoll gradient (Ficoll-Paque, Pharmacia) and suspended at a concentration of $1 \times 10^{6} \mathrm{cell} / \mathrm{ml}$ ) in RPMI medium (Flow Laboratories) supplemented with glutamine, penicillin, streptomycin, and $10 \%$ fetal calf serum.

(a) IFN production. For the induction of IFN- $\alpha 0 \cdot 2$ $\mathrm{ml}$ of Newcastle disease virus (NDV; haemagglutination titre of 500 units) were added to duplicate PBM cultures $(0 \cdot 2 \mathrm{ml}$ cell suspension per vial). Supernatants were harvested 24 hours after infection and stored at $-70^{\circ} \mathrm{C}$. All IFN- $\alpha$ supernatants were dialysed for 7 days at $4^{\circ} \mathrm{C}$ against Sörensen's glycine buffer $\mathrm{pH} 2$ and then for 24 hours against phosphate buffered saline (PBS).

IFN- $\gamma$ was induced by phytohaemagglutinin (PHA, purified, Wellcome) treatment of PBM cultures at final concentrations of $0 \cdot 8,8$, and $20 \mu \mathrm{g} / \mathrm{ml}$. Supernatants were pooled from duplicate cultures at 7 days and stored at $-70^{\circ} \mathrm{C}$.

(b) Interferon assay. The IFN titre of each culture supernatant was assayed by the inhibition of Semliki Forest virus RNA synthesis in confluent monolayers of EBTr cells (IFN- $\alpha$ ) or Hep- 2 cells (IFN- $\gamma$ ). The method is based on that described by McWilliams et 
$a l .{ }^{12}$ IFN- $\alpha$ titres were calculated by reference to the human leucocyte IFN standard MRC 69/19 and expressed as international units (IU) per $\mathrm{ml}$. The lower limit of sensitivity of this assay was $1 \mathrm{IU} / \mathrm{ml}$. IFN- $\gamma$ samples were titrated against a laboratory IFN- $\gamma$ standard, as there is no international standard, and expressed as units $/ \mathrm{ml}$. In the IFN- $\gamma$ assay the lower limit of sensitivity for the laboratory standard was approximately 6 units $/ \mathrm{ml}$.

Serum obtained from patients and controls at the tıme peripheral blood was taken for PBM separation was stored at $-70^{\circ} \mathrm{C}$ and tested on HEp 2 and EBTr cells for IFN. Two-fold dilutions of serum were prepared from a starting dilution of 1:10 to avoid nonspecific inhibition of viral RNA synthesis at lower dilutions. Sera (undiluted) were also screened for IFN- $\alpha$ by an immunoradiometric assay (Celltech). This assay detects IFN $\alpha$ at concentrations $>80$ $\mathrm{IU} / \mathrm{ml}$.

Statistics. (a) Infection and disease exacerbation: the total study period for all patients was divided into 4-week intervals, and chi-squared analysis performed to establish the significance of both infection and disease exacerbations occurring together within the same 4-week period. (b) Interferon production: IFN titres were converted to $\log _{10}$ before analysis, and, if an individual failed to give a detectable IFN response, for the purposes of the analysis the titre was taken to be that of the minimum level of detection of IFN in the appropriate assay. The arithmetic mean and standard deviation were then calculated and the data analysed by the analysis of variance.

\section{Results}

Twenty-four episodes of disease exacerbation occurred (14 systemic and 10 arthritis only), and with 16 of these there was a preceding clinical infection, usually within one week (Table 1). By chi-squared analysis this was a highly significant association $\left(\chi^{2}=20 \cdot 14\right.$,

Table 1 The number of disease exacerbations and those preceded by an infection. Infecting agents shown were isolated in culture apart from 2 streptococci which were identified by unequivocal changes of antistreptolysin $O$ titre

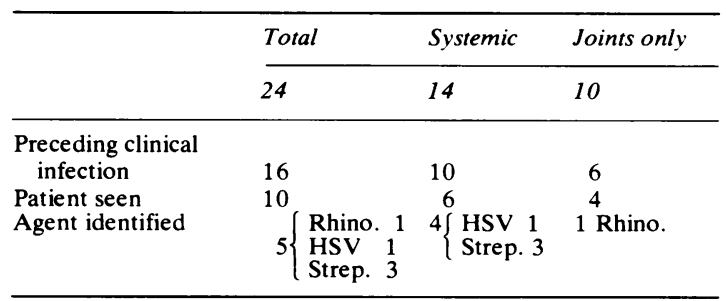

$\mathrm{HSV}=$ herpes simplex virus. $\mathrm{p}<0 \cdot 001)$, being more marked with systemic exacerbation $(p<0.001)$ than joint activity increase alone $(p<0.05)$ (Table 2). All but one of these infections (gastroenteritis) were of the upper respiratory tract 10 common colds and 5 sore throats as defined previously. Among the 10 patients seen within one week of the onset of infection the causative agents were defined in 5 , being rhinovirus during one cold and, with the sore throats, herpes simplex virus (HSV) once and streptococcus 3 times. At no time was $M$. pneumoniae cultured from throat swabs. In 8 of the 24 exacerbations there was no preceding clinical infection, but in 3 of these 8 a member of the household had an upper respiratory tract infection at the same time as the relapse. During the study period there were 38 episodes of respiratory infection, a similar number to that expected from a study of normal children in the Chalke Valley ${ }^{13}$ and fewer than 63

Table 2 Highly significant association of disease flare and preceding clinical infection by chi-square analysis. $\chi^{2}=20 \cdot 14, p<0 \cdot 001$. Predicted occurrence by chance shown in brackets.

\begin{tabular}{|c|c|c|c|}
\hline & Exacerbation & No exacerbation & Total \\
\hline Infection & 16 (7) & $\begin{array}{l}20 \\
(29)\end{array}$ & 36 \\
\hline No infection & $\begin{array}{l}8 \\
(17)\end{array}$ & $\begin{array}{l}82 \\
(83)\end{array}$ & 90 \\
\hline Total & 24 & 102 & 126 \\
\hline
\end{tabular}

Total, $p<0 \cdot 001$. Systemic, $p<0 \cdot 001$. Joints only, $p<0 \cdot 05$.

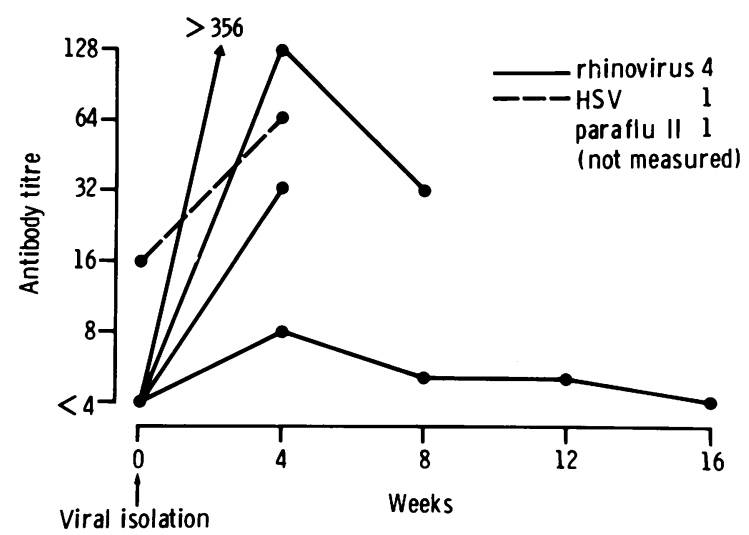
clinical infection

Fig. 1 Viruses isolated in association with an appropriate clinical infection. A diagnostic 4-fold or greater rise in neutralising antibody titre in the 5 tested is shown. No sequential sera were available following the parainfluenza II isolation. 
expected from the study by Hope-Simpson and Higgins in Cirencester ${ }^{14}$ Further, there was less crossinfection from household contacts, the secondary attack rate for common colds contracted from a household contact in our group being $11 \%$ as opposed to $20 \%$ observed in the Paddington study ${ }^{15}$ and $12 \%$ in the Chalke Valley study. ${ }^{13}$

From all common colds and sore throats seen within one week of onset and not due to streptococcal infection the virus isolation rate was $38 \%$ (6 out of

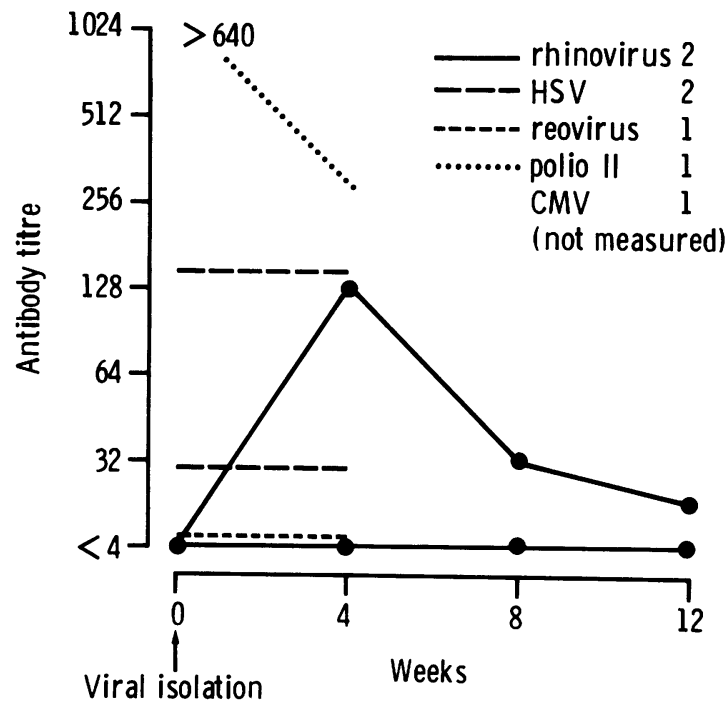

Fig. 2 Seven virus isolations without overt clinical in fection. All but 2 showing no change in neutralising antibody with probable subclinical infection by poliomyelitis II and rhinovirus. Antibodies not measured to cytomegalovirus (CMV).
16). These were rhinovirus 4 times and one each of HSV and parainfluenza II. Thus in 5 episodes it was possible to measure sequential neutralising antibody titres to the virus isolated, and in each there was a 4-fold or greater rise (Fig. 1).

This was in contrast to those isolates obtained in the absence of clinical infection, where only 2 of 7 showed rising or falling titres (Fig. 2).

Antibody titres to a panel of microbial agents (Fig. 3) were similar to those in controls, but there was a trend towards higher and more frequent titres in patients with hypergammaglobulinaemia. However, one individual's antibody titres over 3 months (Fig. 4) showed a brisk response to rhinovirus (without clinical infection) and no response after the symptomless shedding of HSV in the throat. Complement fixing antibody titres to influenza $\mathrm{A}$ and measles virus antigens remained fixed, though the $\mathrm{IgG}$ fell twofold over the 3-month period of observation.

Three patients had sustained levels of 400-800 units ASOT although they did not have pharyngitis and no streptococcus was cultured. However, there were 3 patients who had pharyngitis and whose titre rose to over 800 ; from one of these patients streptococcus group A type 1 was isolated, and the other 2 had received penicillin prior to culture. This organism was not isolated at any other time in the study.

Interferon was not detected in any serum from controls or patients (IFN- $\alpha<10 \mathrm{IU} / \mathrm{ml} ;$ IFN- $\gamma<60$ units $/ \mathrm{ml}$ ). In-vitro IFN production varied considerably in each patient from occasion to occasion (Fig. 5), as it did in the controls from individual to individual. However, the grand mean of the in-vitro IFN- $\alpha$ responses of the patients' peripheral blood mononuclear cells was 10 -fold greater than that of the controls $(p<0 \cdot 01)$. On the other hand the IFN- $\gamma$ responses were similar in both groups.

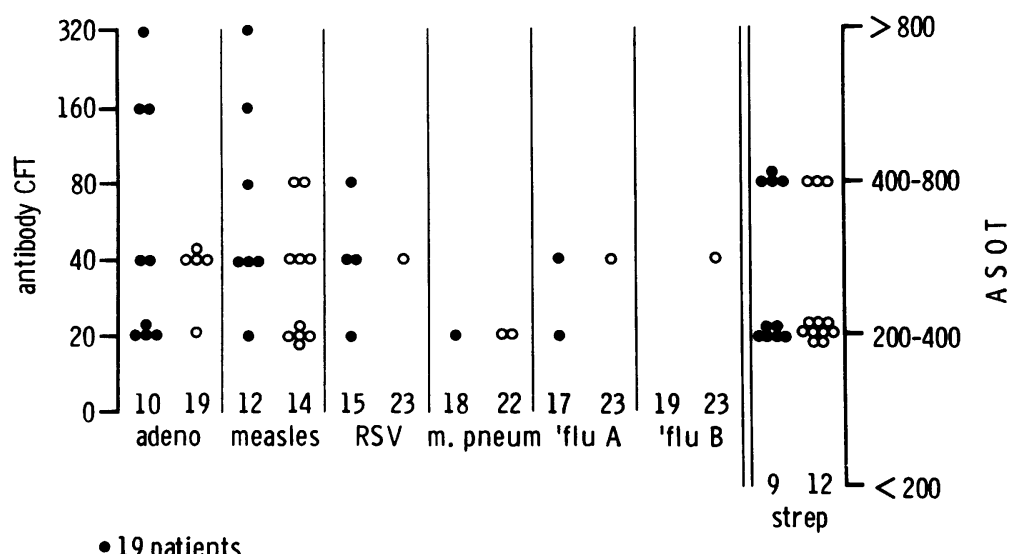

Fig. 3 Antibody titres to microbiol antigens without overt clinical infection. Similar titres of antibodies to a panel of microbial antigens in patients and controls. The numerals on the base line indicate the numbers of individuals with no detectable antibody activity. Antistreptolysin $O$ titre (ASOT) was never $>800$ (haemagglutination inhibition) unless overt clinical infection was present.

- 19 patients

strep 


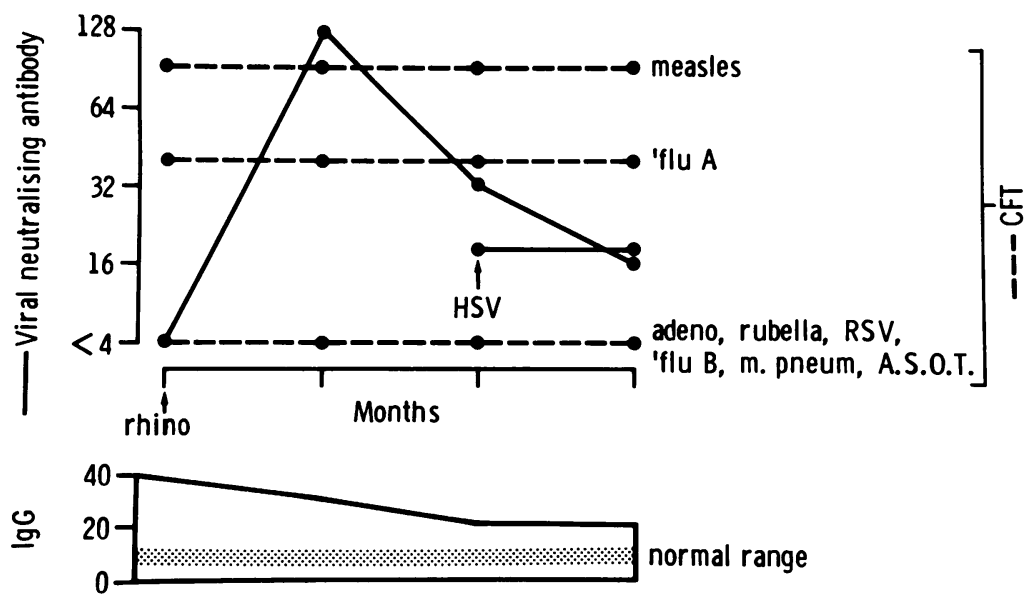

Fig. 4 Antibody responses in 8-year-old girl. Arrows indicate subclinical infection with rhinovirus and asymptomatic shedding of HSV with corresponding neutralising antibody titres (solid lines). Background complement fixing antibody titres (CFT) to a panel of microbial antigens (broken lines) unchanged throughout the 3-month period shown, and no apparent relationship to the total, raised IgG.

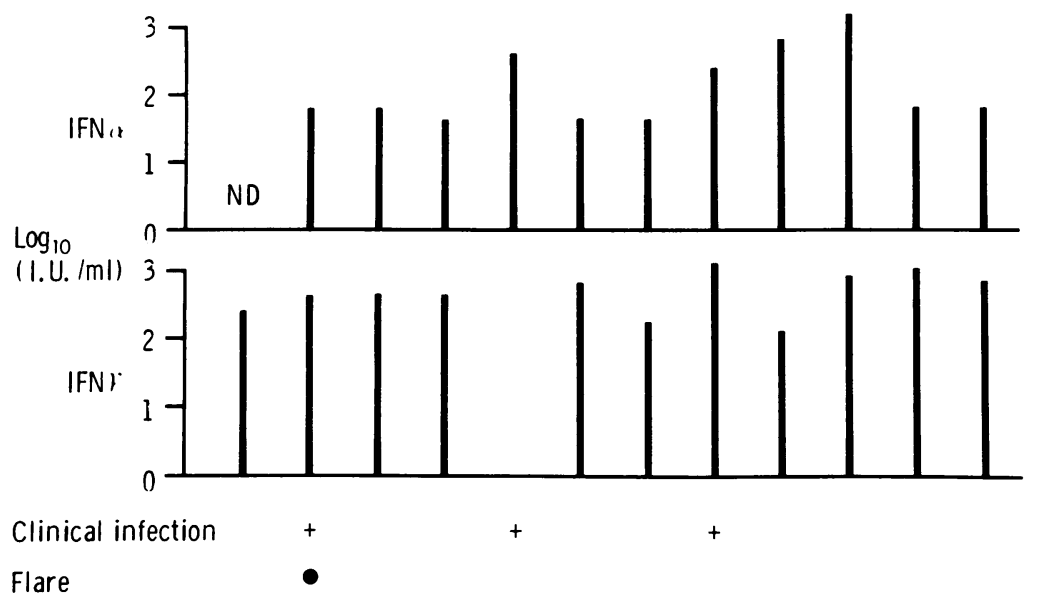

Fig. 5 Male patient, 10 years old. In-vitro IFN- $\alpha$ and IFN- $\gamma$ production by peripheral blood mononuclear cells from a patient studied monthly for 1 year. Marked variation in IFN- $\alpha(N D V$ stimulated) and to a lesser extent peak IFN-y production (PHA stimulated) and no apparent correlation with either disease activity or intercurrent infection.

\section{Discussion}

In our group of children suffering from systemic JCA there was a highly significant association between disease exacerbation and preceding clinical infection, almost all being of the upper respiratory tract. Where laboratory diagnosis was successful, infections were shown to be due to viruses or streptococci. To distinguish between disease exacerbation and the clinical expression of a respiratory infection strict criteria for both were defined as described under 'Methods.' The upper respiratory disease seen was like that seen in healthy children, and a normal brisk rise and subsequent fall in neutralising antibody levels were found. In normal subjects rhinovirus infections rarely cause significant fevers, ${ }^{16}$ and, while parainfluenza II, enteroviruses, and HSV infections may all be associ- ated with fevers and rashes, arthritis is not usually a marked feature. ${ }^{7}$

Acute arthritis following febrile viral-like respiratory syndromes has been described, ${ }^{17}$ but both the respiratory illnesses and infecting viruses were probably different from those in our group of patients.

Some viruses may cause clinical infections which may be confused with systemic JCA. However, infections with rubella, ${ }^{5}$ adenovirus 7 and coxsackie, ${ }^{18}$ cytomegalovirus, mumps, and the arboviruses were not detected in our patients. Antibody responses to infecting viruses and streptococci were appropriate and bore no relationship to total serum $\operatorname{IgG}$ (raised in 7 patients) or drug treatment. No serious infections were seen in the course of the study. Nevertheless, serious infections may occur in patients with active systemic JCA, particularly those taking considerable 
doses of corticosteroids, and these include septicaemia, pneumonia, and recurrent urinary tract infection. The latter was a particular problem in one patient prior to but not during the course of this study, and such repeated urinary tract infections were often followed by exacerbations of disease lasting weeks or months.

The slight trend towards nonspecific elevations of complement fixing antibodies in the 7 hypergammaglobulinaemic patients was of the order of 1 or 2 tube dilutions, none being sufficiently high to be confused with recent infection. However, a recent study from our division has indicated that antibodies to viral capsid antigen (VCA) of the Epstein-Barr virus are detected in children with systemic JCA at an earlier age than other nonsystemic forms of JCA or a control group (Gear A, manuscript in preparation).

Children with active arthritis have a somewhat protected and isolated physical environment at home and school due among other reasons to their fear of injury. This probably accounts for the lower than predicted primary infection rate for common colds and normal ${ }^{15}$ or lower ${ }^{13}$ rate of secondary crossinfection from household contacts.

The marked variation in the in-vitro IFN- $\alpha$ and to a lesser extent IFN- $\gamma$ responses emphasises the problems of interpreting single estimations and the need for longitudinal studies. The higher IFN- $\alpha$ responses in the patients might reflect differing subpopulations of lymphocytes with differing responses to NDV stimulation. Failure to detect serum IFN by either bioassay or immunoradiometric assay also emphasises the difficulty of low-level IFN detection in general; our bioassay for IFN- $\alpha$ was 80 -fold more sensitive than the immunoradiometric assay used, but human serum must be diluted 10 -fold before testing owing to its intrinsic inhibitory effect on the cell culture lines used in the bioassay.

Although the cells of some of our patients occasionally failed to produce IFN- $\alpha$, we did not find a persistent defect, as described by Isaacs et al. in 4 of the 30 patients in their study. ${ }^{19}$ However, they were studying a quite different clinical group of younger children with troublesome recurrent respiratory infection (on whom IFN studies were performed earlier in the course of the infection than our group).

The cells of our youngest patient, a 12-month-old boy, produced no detectable IFN- $\gamma$, though PHA induced proliferation of lymphocytes normally and NDV induced the production of IFN- $\alpha$. There was no apparent relation to his disease, and this could be an age-related phenomenon like that described in neonates. ${ }^{20}$

The exact mechanism involved in the infectionrelated exacerbations seen remains obscure. Theories about it fall broadly into 2 groups: the infec- tion may enhance the chronic disease process by acting as a nonspecific immunological adjuvant, or microbial antigens may induce specific antibodies that cross-react with host structures. ${ }^{21}$

A similar longitudinal study in children at risk of developing asthma showed an association between viral infections of the upper respiratory tract and asthma attacks, ${ }^{22}$ but no direct mechanism could be elucidated. Recent work in mice by Anderson and

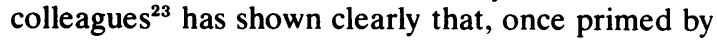
specific antigen and helper $T$ cell contact, the excited B cell may be stimulated to divide and secrete further antibody by antigen-unspecfic factors, probably through the release of growth factors from adjacent helper $\mathrm{T}$ cells and/or macrophages. The range of inciting agents in our study, namely, HSV, rhinovirus, and streptococcus, would tend to support a mechanism of this type.

We thank Dr K. Rogers and Mr M. Vogler for measuring antibody titres to the microbial antigens, Mr Trevor Melboume for his excellent technical help on the IFN assays, Dr D. Taylor-Robinson and Miss P. Furr for the mycoplasma studies, and Miss Caroline Doré for her advice on the statistics.

\section{References}

1 Cassidy J T, Shillis J L, Brandon F B, Sullivan D B, Brackett $R$ G. Viral antibody titres to rubella and rubeola in juvenile rheumatoid arthritis. Pediatrics 1974; 54: 239-44.

2 Calabro J J. Juvenile rheumatoid arthritis. In: McCarty D J, ed. Arthritis and allied conditions. 9th ed. Philadelphia: Lea and Febiger, 1979: 591-601.

3 Tingle A J, Ford D K, Price G E, Kettyls D W G. Prolonged arthritis in identical twins after rubella immunisation. Ann Intern Med 1979; 90: 203.

4 Grahame R, Armstrong R, Simmons N A, Mims C A, Wilton J M A, Laurent $R$. Isolation of rubella virus from synovial fluid in five cases of seronegative arthritis. Lancet 1981; ii: 649-51.

5 Chantler J K, Ford D K, Tingle A J. Persistent rubella infection and rubella-associated arthritis. Lancet 1982; i: 1323-5.

6 Munthe E, ed. The care of rheumatic children. EULAR bulletin. Monograph series no. 3. Basle: EULAR, 1977: 43.

7 Tyrrell D A J. Common colds and related diseases. London: Arnold, 1965: 51.

8 Lewis H M, Parry J V, Davies H A, et al. A year's experience of the rotavirus syndrome and its association with respiratory illness. Arch Dis Child 1979; 54: 339-46.

9 Monto A S, Bryan E R. Microneutralisation test for detection of rhinovirus antibodies. Proc Soc Exp Biol Med 1974; 145: 690-4.

10 Rawls W E, Iwamoto K, Adam E, Melnick J L. Measurement of antibodies to herpes virus types 1 and 2 in human sera. $J$ Immunol 1970; 104: 599-606.

11 Hasony H J, Macnaughton M R. Prevalence of human coronavirus antibody in the population of Southern Iraq.J Med Virol 1982; 9: 209-16.

12 McWilliaims M, Finkelstein M S, Allen P T, Giron D J. Assay of chick interferon by the inhibition of viral ribonucleic acid synthesis. Appl Microbiol 1971; 21: 959-61.

$13 \mathrm{Lidwell} \mathrm{OM}$, Sommerville T. Observations on the incidence and distribution of the common cold in a rural community during 1948 and 1949. J Hyg (Camb) 1951; 49: 365.

14 Hope-Simpson R E, Higgins P G. A respiratory virus study in Great Britain: review and evaluation. Prog Med Virol 1969; 11: 354-407. 
15 Brimblecombe F S W, Cruikshank R, Masters P L, Reid D D, Stewart G T. Family studies of respiratory infections. $\mathrm{Br}$ Med J 1958; i: 119-28.

16 Tyrrell D A J. Clinical clues in virus infections. Br Med J 1963; i: 493-6.

17 Panush R S. Acute arthritis associated with febrile viral-like respiratory syndromes. J Rheumatol 1974; 1: 299-307.

18 Rahal J J, Millian S J, Noriega E R. Coxsackie virus and adenovirus infection. Association with acute febrile and juvenile rheumatoid arthritis. JAMA 1976; 235: 2496-501.

19 Isaacs D, Clarke J R, Tyrrell D A J, Webster A D B, Valman H B. Deficiency of production of leucocyte interferon (interferon- $\alpha$ ) in vitro and in vivo in children with recurrent respiratory tract infections. Lancet 1981; ii: 950-2.

20 Bryson Y J, Winter H S, Gard S E, Fischer T J, Stiehm E R. Deficiency of immune interferon production by leukocytes of normal newborns. Cell Immunol 1980; 55: 191-200.

21 Glynne LE. In: Dumonde D C, ed. Infection and immunology in the rheumatic diseases. Oxford: Blackwell, 1976: 75.

22 Frick O L, German D F, Mills J. Development of allergy in children. 1. Association with virus infections. J Allergy Clin Immunol 1979; 63: 228-41.

23 Andersson J, Schreier M H, Melchers F. T-cell-dependent B-cell stimulation is $\mathrm{H}-2$ restricted and antigen dependent only at the resting B-cell level. Proc Natl Acad Sci USA 1980; 77: 1612-6.

\section{Book review}

Advances in Assessing Rheumatoid Arthritis: Symposium/Workshop at the London Hospital, 17-18 March 1983. British Journal of Rheumatology Supplement 1983. Available from Bailliere Tindall, 1 Vincent Square, London SW1, $£ 8.00$ including postage and packing.

I was fortunate to be invited to attend this symposium and commend its published proceedings for 2 reasons.

In the first place the design of the programme was imaginative and highly efficient, providing an excellent model for clinical workshops. Preconference questionnaires about the quality of clinical trial reports were distributed to the participants and results were analysed in detail at the meeting. At the opening session invited lecturers addressed 4 aspects of the problem-statistics, judgment analysis, radiology, and the assessment of disability. The meeting was then divided into a number of group discussions, each with its chairman, reporter, and introductory speakers, which thrashed out prescribed topics-definition and characterisation of rheumatoid arthritis, the nature of drugs to be tested, reporting clinical trials, multicentre trial management, and measurement of patient and other outcomes. In the final session the results of these group discussions were presented and debated. I can think of no better way for an active interchange of ideas.

Secondly, the ideas thrown up were interesting and sometimes provocative. For example, R. Peto, speaking from a wealth of experience, proposed that any controlled trial of disease-modifying drugs should involve several dozen rheumatologists studying 2000 patients over a 5-year period, but using very simple assessments of compliance, toxicity, and therapeutic benefit. C. R. B. Joyce and K. R. Hammond, using a mathematical model, showed how the different factors of knowledge and consistency can influence clinical judgment, a theme developed by other speakers. J. F. Fries discussed in depth modern techniques of outcome assessment, in which disability is an important but by no means the only consideration. From the group discussion on the reporting of clinical trials emerged an important checklist of data which should be presented in such reports. The point was strongly made that most published clinical studies have been too seriously deficient in requirements to draw valid conclusions about therapeutic response. The interest generated by the symposium might perhaps have been enhanced by some consideration of assessing therapeutic agents other than drugs-physical treatment, surgery, or recent immunological tours-de-force such as lymphocyte depletion by one way or another, although the same principles of evaluation no doubt apply.

During the meeting I could not help reflecting on the comparison with another common rheumatic disorder-gout-in which I have taken an interest over the years. Here we have considerable knowledge about the causative agent, hyperuricaemia, which can be tidily measured in assessing the effect of 'disease-modifying' drugs such as allopurinol, with an almost certain knowledge of ultimate 'patient outcome'. It did not take 2000 patients to make the point: our original UK study on allopurinol dealt with 4 patients only, and was pretty conclusive. In rheumatoid arthritis we have no uric acid to estimate and certainly no allopurinol to deal with it. Time will change all this and one or two of our younger rheumatologists, chancing upon this dust-covered Supplement in years to come, will marvel at the skill and dedication at present being given to what is after all only the fringe of the problem. Parturient montes, nascetur ridiculus mus.

Nevertheless, we have to chase the wee mouse as he runs at the moment, and we should do it properly. The publication is well referenced and will undoubtedly be a definitive work on the subject for the next few years. It should be at the elbows of trialists and editors alike. 